\title{
Evaluasi Teknik Filtering Contrast Enhancement dan Edge Sharpening untuk Pengolahan Citra Ultrasonografi Prostat
}

\author{
Ni Larasati Kartika Sari ${ }^{*}$, Ryscha Dwi Iriani ${ }^{1}$, Erna Yunika ${ }^{1}$, Budi Santoso ${ }^{1}$ \\ ${ }^{1}$ Program Studi Fisika, Fakultas Teknik dan Sains, Universitas Nasional, Jakarta \\ *Korespondensi penulis: nilarasati@civitas.unas.ac.id \\ (Received: 11-03-2021; Revised: 03-05-2021; Accepted: 20-05-2021)
}

\begin{abstract}
Abstact. One of the modality to detect prostate's abnormalities is ultrasonography (USG). Indonesia still relies on 2D USG images despite its weaknesses. In this research, image processing called Computer-Aided Diagnostic $(C A D)$ was performed on $2 D$ USG prostate images. This research is a basic CAD research to improve the quality of $2 D$ USG images with various combination of image procesing methods. Evaluation of the processed images are performed by not only SNR method, but also evaluation from clinicians. Twenty prostate images were used with normal and abnormal diagnosis. Image processing methods used are median filter, wiener filter, gaussian filter, CLAHE (Contrast Limited Adaptive Histogram Equalization) contrast enhancement and image sharpening. Those methods were combined so there are three combinations to be evaluated. Among 3 combinations, gaussian filter combination has the highest SNR in normal and abnormal images. But, qualitative evaluation performed by clinicians shows that median filter combination has the best visualization of prostate capsule and prostate size. Evaluation from comparing pixel value and prostate size between normal and abnornal images shows that median filter combination has the biggest differences, 13.11, makes it the best combinaton to show different visualization of normal and abnormal prostate.
\end{abstract}

Keywords: contrast enhancement, gaussian filter, median filter, wiener filter, USG images, SNR.

\begin{abstract}
Abstrak. Salah satu modalitas untuk mendiagnosis abnormalitas prostat adalah pencitraan ultasonografi (USG). Sejauh ini, Indonesia masih mengandalkan pencitraan USG dua dimensi kendati memiliki banyak kekurangan. Pada penelitian ini dilakukan pengolahan citra digital yang dikenal dengan Computer-Aided Diagnostic (CAD) terhadap citra dua dimensi hasil USG prostat. Penelitian ini merupakan penelitian dasar CAD yang meningkatkan kualitas citra USG dua dimensi dengan variasi dan kombinasi metode pengolahan citra. Selain evaluasi dengan pengukuran SNR, penelitian ini juga melibatkan evaluasi visual dari klinisi. Citra yang digunakan adalah 20 citra prostat dengan diagnosis normal dan abnormal. Metode pengolahan citra yang digunakan adalah filter median, filter wiener, filter gaussian, peningkatan kontras dengan CLAHE (Contrast Limited Adaptive Histogram Equalization), serta penajaman citra yang dikombinasikan sehingga terdapat tiga kombinasi untuk di evaluasi. Berdasarkan nilai SNR kombinasi dengan filter gaussian menghasilkan nilai SNR tertinggi, baik pada citra USG prostat normal dan abnormal. Namun, secara kualitatif kombinasi dengan filter median menghasilkan gambaran visual kapsul prostat dan ukuran prostat yang paling baik. Berdasarkan hasil dari ketiga metode kombinasi, kombinasi dengan filter median menghasilkan perbedaan nilai piksel terbesar antara citra abonormal dengan normal, yaitu 13.11, yang berarti mampu menghasilkan perbedaan visualisasi yang baik antara citra prostat normal dan citra prostat abnormal.
\end{abstract}

Kata Kunci : contrast enhancement, filter gaussian, filter median, filter wiener, citra USG, SNR.

\section{PENDAHULUAN}

Pencitraan memegang peranan yang sangat penting di bidang kedokteran terutama dalam mediagnosa penyakit. Peralatan kedokteraan seperti Computed Tomogrphy Scan (CT- 
Scan), Magnetic Resonance Imaging (MRI), Ultrasonografi (USG) merupakan modalitas pencitraan sebagai sarana untuk memudahkan dalam mediagnosa kelainan atau penyakit. USG adalah satu dari modalitas pencitraan untuk mendiagnosis organ internal manusia yang menggunakan pantulan gelombang suara frekuensi tinggi [1]. Pemeriksaan USG relatif lebih aman dibanding modalitas lain yang memanfaatkan energi dari radiasi pengion. Salah satu pemanfaatan USG adalah untuk pencitraan organ prostat. USG prostat biasanya digunakan sebagai pemandu dalam penempatan jarum biopsi [2]. USG prostat untuk diagnosis kanker juga banyak dilakukan namun memiliki keterbatasan dalam membedakan maglinansi pada prostat [2].

Visual citra USG memiliki kelemahan, yaitu terdapat bintik noise cenderung menutupi visibilitas, serta memiliki kontras rendah yang mengurangi kemampuan pengamat untuk menginterpretasikan informasi yang sebenarnya. Untuk meningkatkan kualitas citra USG, sekaligus meningkatkan visibilitas abnormalitas dan anatomi lainnya, dapat dilakukan pengolahan citra (image processing) dengan berbagai teknik. Pengolahan citra USG dapat meningkatkan tampilan visual dari citra USG, meningkatkan fitur, dan mendapatkan karakteristik citra USG yang lebih baik, sehingga dapat menghasilkan diagnosis yang tepat [3]. Untuk meningkatkan kualitas citra dapat digunakan filter untuk menghapus noise, sehingga menghasilkan citra yang optimal dengan tingkat ketajaman kontras yang baik [4]. Pengunaan filter pada citra USG dapat menghilangkan speckle noise dan memperbaiki detail karakteristik citra asli [5].

Sejauh ini, USG dua dimensi merupakan salah satu modalitas diagnostik yang paling banyak tersedia, khususnya di rumah sakit pelosok maupun klinik di Indonesia [6]. Walaupun demikian, USG dua dimensi memiliki banyak kekurangan. Pengurangan tingkat noise speckle dengan menggunakan filter dapat membantu proses diagnosis [7]. Oleh karena itu penelitian ini memanfaatkan aplikasi pengolahan citra yang dapat membantu peningkatan kualitas citra USG dua dimensi prostat. Penelitian ini merupakan penelitian dasar Computer Aided Diagnosis (CAD) yang mengkombinasikan filtering, peningkatan kontras, dan penjaman tepi citra yang sederhana. Penilaian terhadap kualitas citra dilakukan secara kuantitaif dengan mengukur SNR, kualitatif dengan evaluasi visual melalui kuesioner kepada klinisi, serta dilakukan pula pengukuran luas area prostat pada citra normal dan abnormal untuk menilai apakah progam pengolahan citra telah meningkatkan visualisasi abnormalitas pada citra. Penelitian ini diharapkan dapat menjadi solusi untuk mengurangi keterbatan visualisasi citra USG dua dimensi.

\section{METODE PENELITIAN}

Pada riset ini digunakan 20 citra USG prostat dengan diagnosis normal dan abnormal, masing-masing 10 citra, berformat DICOM. Pengolahan citra pertama kali dilakukan dengan mengubah format DICOM menjadi format tiff.

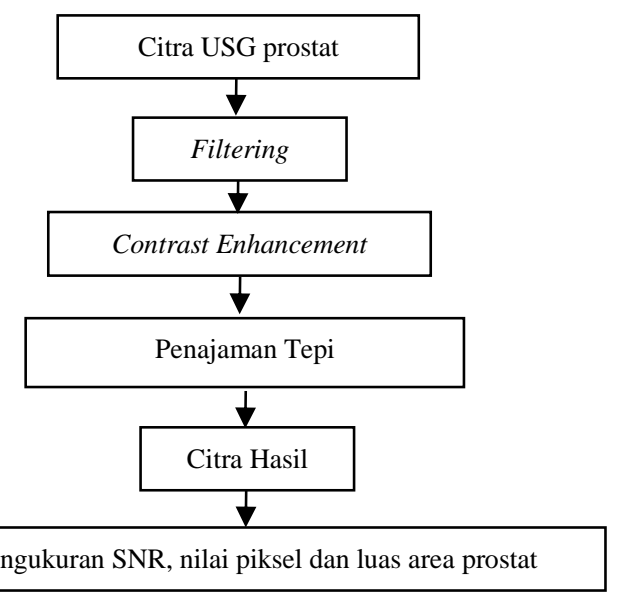

GAMBAR 1. Diagram alir program pengolahan citra USG prostat 
Selanjutnya, citra dengan format tiff diolah melalui tiga proses, yaitu filtering, contrast enhancement, dan sharpening, secara berurutan. Diagram alur progam pengolahan citra dapat dilihat pada gambar 1.

Pada riset ini, teknik filtering yang digunakan adalah filter median, filter wiener, dan filter gaussian, sedangkan, teknik contrast enhancement yang digunakan adalah CLAHE (Contrast Limited Adaptive Histogram Equalization). Sehingga terdapat tiga kombinasi filtering dan contrast enhancement seperti ditunjukkan pada tabel 1.

TABEL 1. Kombinasi filtering dan contrats enhancement.

\begin{tabular}{cl}
\hline Filtering / Contrast Enhancement & \\
\hline Filter Median + CLAHE & Kombinasi 1 \\
Filter Gaussian + CLAHE & Kombinasi 2 \\
Filter Wiener + CLAHE & Kombinasi 3 \\
\hline
\end{tabular}

Selanjutnya pengukuran kualitas dan karakterisasi citra dilakukan pada citra hasil pemprosesan tiga langkah di atas. Kualitas citra yang diukur adalah Signal to Noise Ratio (SNR), sedangkan karaktersiasi citra yang diukur adalah nilai piksel rata-rata dan luas daerah. Pengukuran SNR dilakukan dengan menganggap sinyal adalah nilai piksel rata-rata dari citra setelah pengolahan, dan noise adalah selisih nilai piksel rata-rata dari citra sebelum dan sesudah pengolahan. Selanjutnya dilakukan evaluasi nilai SNR terbaik di antara tiga kombinasi. Sementara itu, karakterisasi citra dilakukan dengan membuat region of interest (ROI) pada daerah prostat di citra, lalu dilakukan pengukuran nilai piksel dan luas daerah. Selanjutnya, dilakukan penghitungan selisih luas daerah dan nilai piksel antara citra prostat normal dan abnormal dan dievaluasi, kombinasi mana yang menghasilkan perbedaan paling besar.

Selain itu, dilakukan pula evaluasi secara visual terhadap hasil pemrosesan citra dengan memberikan kuesioner ke delapan orang klinisi. Kuesioner berisi pertanyaan mengenai visual citra hasil pemprosesan, terutama visualisasi kapsul prostat dan ukuran prostat. Klinisi diberi opsi untuk memilih sangat buruk, buruk, cukup, baik, sangat baik. Hasil kuesioner selanjutnya di analisis dengan metode likert dengan skor 1 untuk sangat buruk, 2 untuk buruk, 3 untuk cukup, 4 untuk baik, dan 5 untuk sangat baik.

\section{HASIL DAN PEMBAHASAN}

Hasil pengolahan citra normal ditampilkan pada gambar 2, sementara hasil pengolahan citra abnormal ditunjukkan pada gambar 3. Terlihat bahwa di antara ketiga proses, proses peningkatan kontras adalah proses yang paling memberikan efek berbeda secara visual. Terlihat jelas peningkatan kontras dan tingkat kecerahan antara citra sebelum ( $2 b$ dan $3 b$ ) dengan citra sesudah peningkatan kontras ( $2 \mathrm{c}$ dan $3 \mathrm{c}$ ). Perbedaan tingkat keabuan antara objek dengan latar menjadi lebih jelas pada citra hasil penerapan contrast enhancement.

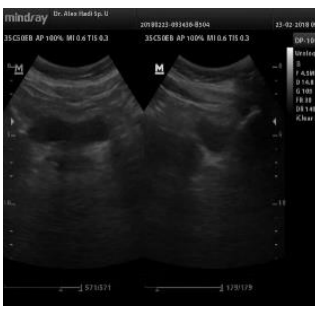

(a)

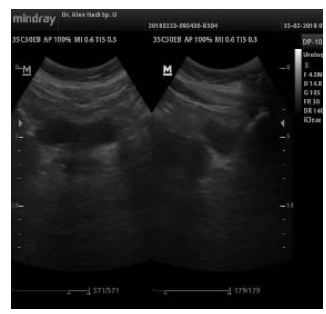

(b)

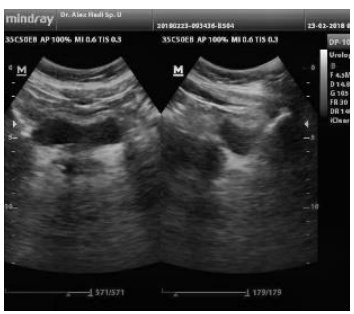

(c)

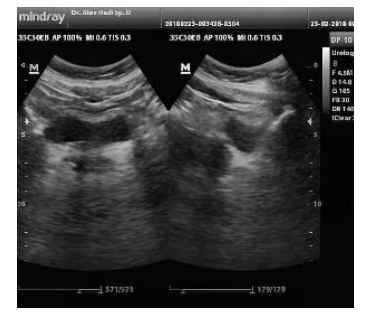

(d)

GAMBAR 2. Citra prostat normal (a) citra asli, (b) citra setelah dilakukan filtering, (c) citra setelah dilakukan contrast enhancement, (d) Citra setelah dilakukan sharpening.

Perbandingan hasil dari ketiga metode filter (Median, Gaussian, Wiener), CLAHE, dan penajaman tepi dapat dilihat pada gambar 4. Dari gambar 4, dapat kita amati bahwa penggunaan filter, contrast enhancement dan penajaman citra megubah kontras dan 
ketajaman citra. Terlihat bahwa kombinasi dengan filter gaussian pada gambar $4 \mathrm{~d}$ menghasilkan citra yang lebih kabur dibandingkan dengan kombinasi dengan filter median dan wiener, terutama pada bagian objek. Hal ini sesuai dengan cara kerja filter gaussian yaitu menghilangkan noise dengan mengaburkannya [8].

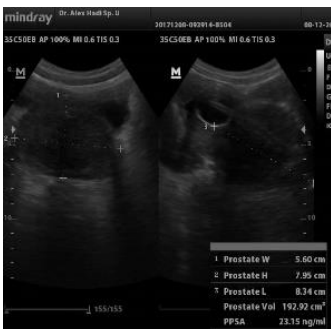

(a)

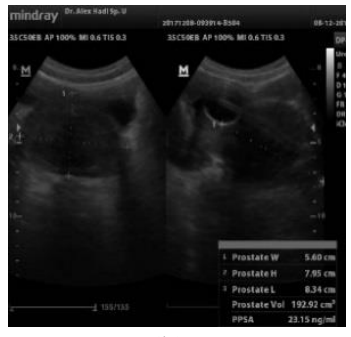

(b)

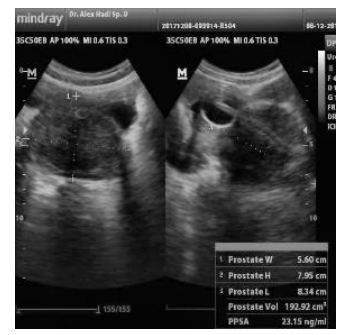

(c)

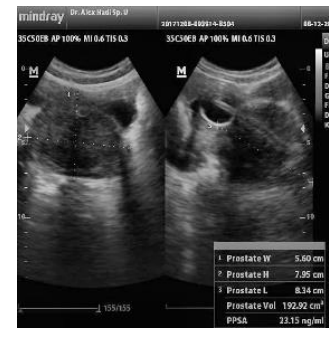

(d)

GAMBAR 3. Citra prostat abnormal (a) citra asli, (b) citra setelah dilakukan filtering, (c) citra setelah dilakukan contrast enhancement, (d) Citra setelah dilakukan sharpening.

Proses blurring yang dilakukan filter gaussian tidak hanya menghilangkan noise, namun juga memberi efek ke pengaburan detail objek [9]. Sementara itu, filter median yang merupakan filter non linear, bekerja dengan tetap menjaga detail di tepi objek, sehingga citra hasil tidak mengalami pengaburan [10]. Filter median tidak memiliki algoritma yang komplek merupakan filter yang paling penting dalam mengurangi speckle noise yang ada pada citra USG [11]. Filter wiener merupakan salah satu teknik untuk restorasi citra yang berfungsi memperbaiki citra yang kabur secara adaptif, sehingga akan tetap menjaga detail citra [12].

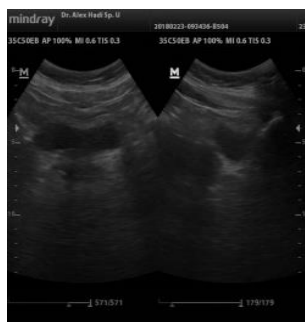

(a)

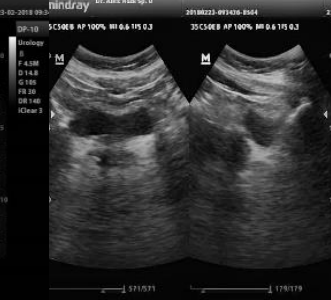

(b)

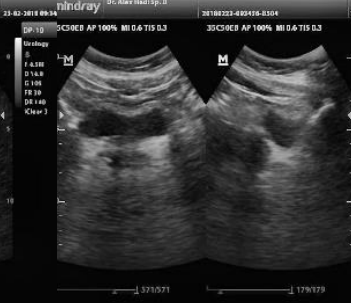

(c)

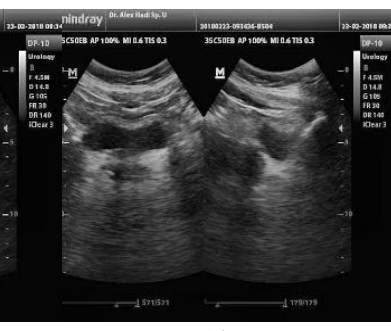

(d)

GAMBAR 4. Perbandingan hasil citra (a) citra asli (b) citra hasil kombinasi dengan filter median, (c) citra hasil kombinasi dengan filter wiener, dan (d) citra hasil kombinasi dengan filter gaussian.

Selanjutnya pengukuran SNR dilakukan pada citra hasil pengolahan. Nilai SNR dari ketiga kombinasi metode dapat dilihat pada tabel 2 dan gambar 5. Terlihat bahwa kombinasi 3 yang melibatkan filter gaussian memiliki nilai SNR tertinggi, baik pada citra normal maupun abnormal. Hal ini menunjukkan citra hasil kombinasi dengan filter gaussian memiliki noise yang paling rendah.

TABEL 2. Nilai Rata-rata SNR dari tiga kombinasi pada citra normal dan abnormal.

\begin{tabular}{cccc}
\hline Citra & $\begin{array}{c}\text { Kombinasi 1 } \\
\text { (filter } \text { median + CLAHE) }\end{array}$ & $\begin{array}{c}\text { Kombinasi 2 } \\
\text { (filter wiener + CLAHE) }\end{array}$ & $\begin{array}{c}\text { Kombinasi 3 } \\
\text { (filter } \text { gaussian + CLAHE) }\end{array}$ \\
\hline Normal & 269.91 & 537.00 & 1179.08 \\
Abnormal & 106.61 & 433.61 & 1047.97 \\
\hline
\end{tabular}

Namun, nilai SNR yang tinggi belum tentu menghasilkan tampilan visual yang paling baik. Pada gambar 3 terlihat bahwa tiap kombinasi menghasilkan citra dengan tampilan berbeda. Untuk mengevaluasi hasil pengolahan citra secara kualitatif telah disebar kuesioner ke dokter klinisi, hasil kuesioner dapat dilihat pada tabel 3.

Berdasarkan kuesioner kombinasi metode filter median + CLAHE adalah kombinasi yang dapat menghasilkan tampilan kapsul prostat dan ukuran prostat yang paling baik. Metode filter median bekerja dengan cara mengurangi noise namun tidak mengaburkan batas tepi 
objek [13]. Sehingga noise yang terdapat pada citra berkurang namun batas organ prostat pada citra masih dapat terlihat. CLAHE bekerja dengan cara meningkatkan kontras dari citra. Peningkatan konrtras dilakukan tidak secara global melainkan perobjek. Sehingga perbedaan kontras objek dan latar semakin jelas. Penggunaan CLAHE setelah filter median dapat meningkatkan kontras objek tanpa memperkuat noise.

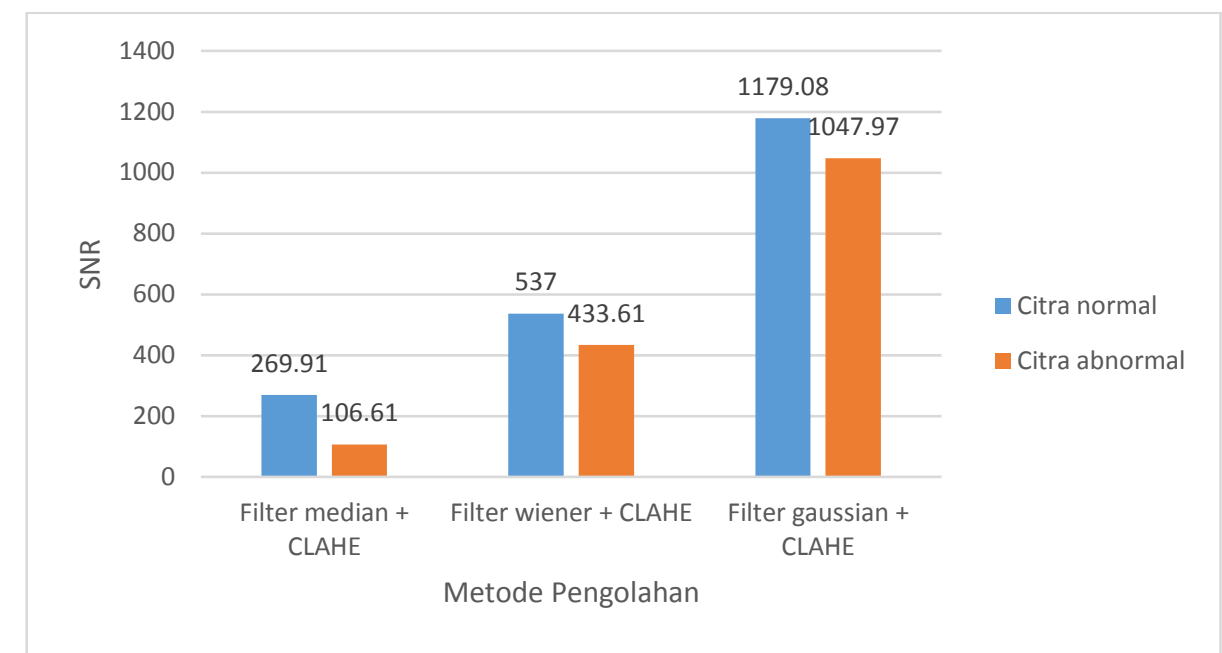

GAMBAR 5. Grafik SNR untuk tiga kombinasi pada citra normal dan abnormal.

TABEL 3. Tabel kuesioner.

\begin{tabular}{|c|c|c|c|c|c|c|c|c|c|c|c|c|c|c|c|}
\hline \multirow[t]{2}{*}{ Pertanyaan } & \multicolumn{5}{|c|}{$\begin{array}{c}\text { Kombinasi } 1 \\
\text { (filter median + CLAHE) }\end{array}$} & \multicolumn{5}{|c|}{$\begin{array}{c}\text { Kombinasi } 2 \\
\text { (filter wiener + CLAHE) }\end{array}$} & \multicolumn{5}{|c|}{$\begin{array}{c}\text { Kombinasi } 3 \\
\text { (filter gaussian + CLAHE) }\end{array}$} \\
\hline & SBU & BU & $\mathrm{C}$ & B & SB & SBU & BU & $\mathrm{C}$ & B & SB & SBU & BU & $\mathrm{C}$ & B & SB \\
\hline $\begin{array}{l}\text { Kapsul } \\
\text { prostat }\end{array}$ & - & - & 27 & 47 & 97 & - & - & 33 & 80 & 38 & - & 1 & 60 & 81 & 17 \\
\hline $\begin{array}{l}\text { Ukuran } \\
\text { prostat }\end{array}$ & - & - & 26 & 46 & 97 & - & - & 33 & 79 & 39 & - & - & 60 & 82 & 17 \\
\hline Total & - & - & 33 & 93 & 194 & - & - & 66 & 159 & 77 & - & 1 & 120 & 163 & 34 \\
\hline Skor & \multicolumn{5}{|c|}{$4.5=$ Baik } & \multicolumn{5}{|c|}{$3.8=$ Cukup } & \multicolumn{5}{|c|}{$3.7=$ Cukup } \\
\hline
\end{tabular}

*Keterangan tabel 3, SB: sangat buruk, BU: buruk, C: cukup, B: baik, SB: sangat baik

Kombinasi filter gaussian dan CLAHE menghasilkan tampilan kapsul prostat dan ukuran prostat yang paling buruk berdsarkan kuesioner. Filter gausian menghilangkan noise dengan cara memperhalus citra. Hal tersebut menyebabkan terjadinya batas-batas gambaran yang kabur. Sehingga batasan objek prostat tampak kurang jelas pada citra.

Berdasarkan nilai SNR pada tabel 2 dan grafik SNR pada gambar 5, nilai SNR tertinggi untuk citra prostat normal dan abnormal adalah kombinasi filter gaussian dengan CLAHE. Nilai SNR menggambarkan kemampuan metode untuk menghilagnkan noise. Hal tersebut berarti filter gausian adalah filter yang paling baik dalam mengurangi noise pada citra USG. Namun berdasarkan kuesioner pada tabel 3, penggunaan filter gaussian justru menghasilkan citra dengan tampilan kurang bagus. Hal tersebut dikarenakan filter gaussian menghilangkan noise dengan memperhalus citra, sehingga noise pada citra berkurang namun juga tepi-tepi objek menjadi kabur.

Pengukuran karakteristik citra dilakukan dengan mengambil ROI pada daerah prostat di citra seperti pada gambar 6. Pengukuran ini dilakukan untuk mengetahui pakah terdapat perbedaan karakteristik antara citra normal dengan abnormal. Hasil pengukuran karakteristik citra dapat dilihat pada Tabel 4.

TABEL 4. Karakteristik citra prostat normal dan abnormal

\begin{tabular}{lrrrrrl}
\hline \multirow{2}{*}{ Citra } & \multicolumn{3}{c}{ Nilai Piksel Rata-Rata } & \multicolumn{3}{c}{ Luas Daerah } \\
\cline { 2 - 7 } & 1 & 2 & 3 & 1 & 2 & \multicolumn{1}{c}{3} \\
\hline Prostat normal & 74.66 & 73.59 & 76.07 & 4282.35 & 4602.92 & 4886.38 \\
Prostat Abnormal & 61.55 & 62.41 & 64.75 & 15968.64 & 17136.53 & 17201.20 \\
\hline
\end{tabular}


Berdasarkan tabel 4 serta gambar 7 dan 8 , nilai piksel dan luas area prostat pada citra normal lebih besar dibandingkan citra abnormal. Pada ketiga metode pengolahan citra, pasien yang mengalami pembesaran protat (prostat abnormal) terdapat rongga sinus yang mengeluarkan cairan kelenjar pada ruang sinus prostat sehingga pada citra tampak lebih homogen dibanding pada citra normal. Warna yang lebih homogen akan menghasilkan nilai piksel yang rendah. Nilai luas daerah prostat pada ketiga metode pengolahan citra juga sesuai dengan diagnosis klinisi. Prostat yang mengalami pembesaran akan tampak lebih besar pada citra dibandingkan prostat normal.
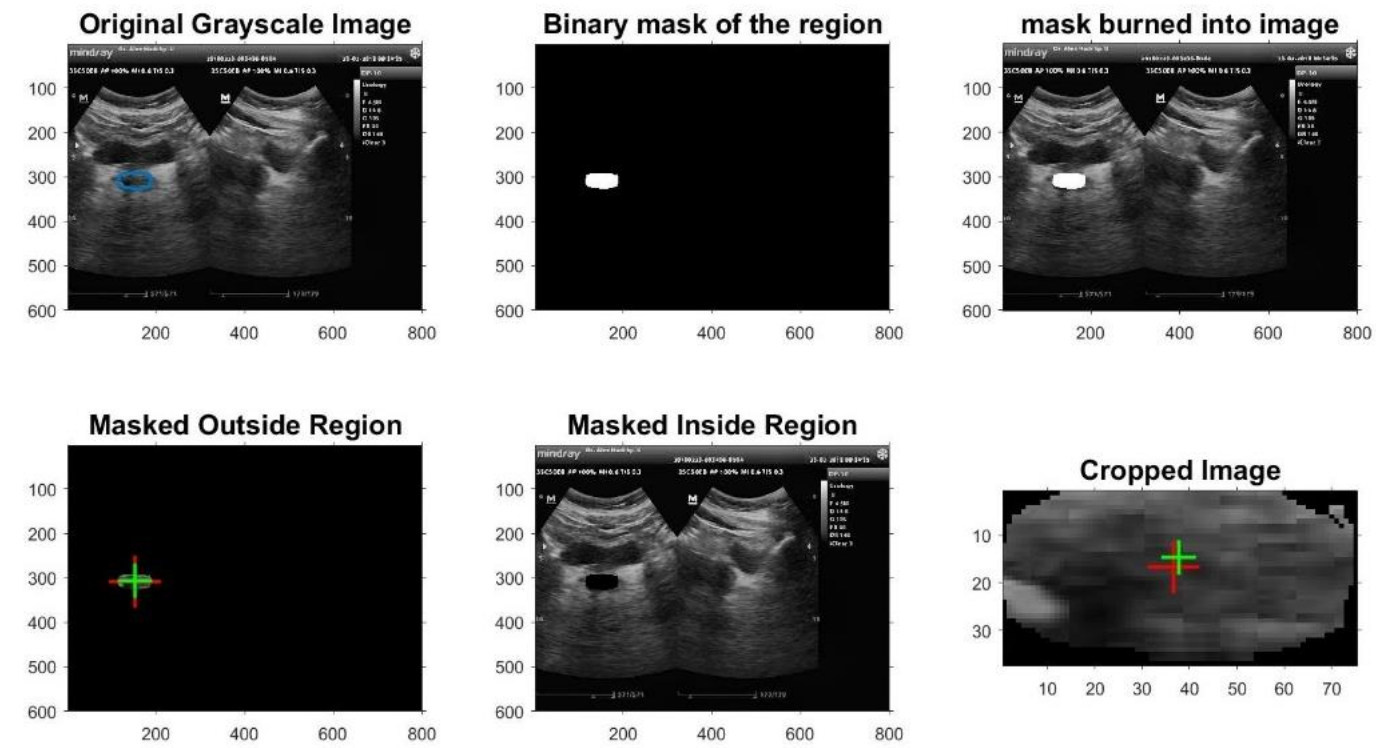

GAMBAR 6. Proses ROI untuk pengukuran luas dan nilai piksel.

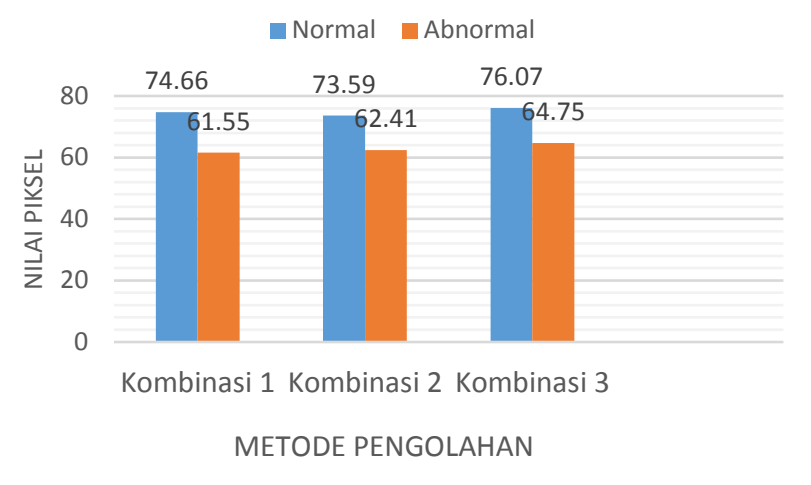

GAMBAR 7. Grafik nilai piksel citra untuk berbagai metode pengolahan.

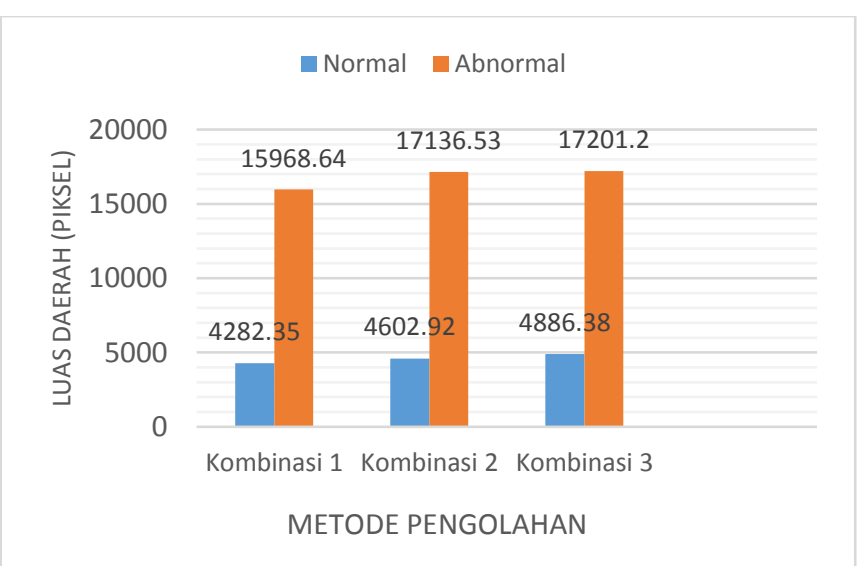

GAMBAR 8. Grafik luas daerah prostat untuk berbagai metode pengolahan. 
Pada tabel 4 dan gambar 7 serta 8 juga terlihat bahwa tiap metode pengolahan citra menghasilkan perbedaan nilai piksel normal dan abnormal. Kombinasi 1 yang terdiri dari filter median dan CLAHE menghasilkan perbedaan nilai piksel normal dan abnormal sebesar 13.11. Kombinasi 2 yang terdiri dari filter weiner dan CLAHE menghasilkan perbedaan nilai piksel normal dan abnormal sebesar 11.18. Kombinasi 3 yang terdiri dari filter gaussian dan CLAHE menghasilkan perbedaan nilai piksel normal dan abnormal sebesar 11.32. Dari ketiga metode tersebut, diperoleh bahwa kombinasi 1 menghasilkan perbedaan nilai piksel paling besar, yang berarti kombinasi 1 mampu menghasilkan perbedaan visualisasi yang baik antara citra dengan prostat normal dan citra prostat abnormal. Hal ini sesuai pula dengan hasil kuesioner klinisi yang menyatakan bahwa kombinasi 1 menghasilkan visualisasi yang paling baik. Citra yang menggunakan filter gaussian tampak blur karena pada filter gaussian bekerja menghaluskan noise dengan mengabaikan sinyal frekuensi rendah.

\section{KESIMPULAN}

Berdasarkan hasil pengolahan citra terhadap sejumlah citra USG prostat baik normal maupun abnormal dengan menggunakan 3 kombinasi metode pengolahan citra dan evaluasi visual dari klinisi maka dapat disimpulkan bahwa, berdasarkan nilai SNR, kombinasi filter gaussian dan CLAHE menghasilkan nilai SNR tertinggi, baik pada citra USG prostat normal dan abnormal. Ditunjukkan pula bahwa, kombinasi filter median dan CLAHE menghasilkan perbedaan nilai piksel terbesar yaitu, 13.11, yang berarti kombinasi ini mampu menghasilkan perbedaan visualisasi yang baik antara citra dengan prostat normal dan citra prostat abnormal. Sementara itu, berdasarkan luas daerah antara prostat normal dan prostat abnormal, luas prostat abnormal lebih besar dibandingkan prostat normal. Secara kualitatif, kombinasi filter median dengan CLAHE menghasilkan gambaran visual kapsul prostat dan ukuran prostat yang paling baik, sesuai dengan hasil pengamatan visual klinisi.

\section{DAFTAR PUSTAKA}

[1] Y. M. Y. Abdallah, A. S. Algaddal, and M. A. Alkhir, "Enrichment of Ultrasound Images using Contrast Enhancement Techniques Enrichment of Ultrasound Images using Contrast Enhancement Techniques," no. January, 2015.

[2] E. J. Halpern, "Contrast-Enhanced Ultrasound Imaging of Prostate Cancer," vol. 8, pp. 29-37, 2006.

[3] P. Suresh and S. Padmavathy, "Image enhancement through contrast improvement in ultrasound image using matlab," vol. 1, no. 8, pp. 11-13, 2016.

[4] B. Sharathbabu, S. Banu, S. Kumar, and D. S., "Denoising ultrasound scan image from speckle noise," Int. J. Pharm. Technol., vol. 8, pp. 26306-26311, Dec. 2016.

[5] R. Sivakumar, "Comparative Study of Speckle Noise Reduction of Ultrasound Bscan Images in Comparative study of Speckle Noise Reduction of Ultrasound Bscan Images in Matrix Laboratory Environment," no. September, 2015.

[6] D. A. N. Rekonstruksi, D. A. N. Visualisasi, D. Usg, P. Pengkajian, and T. Farmasi, "Pengembangan sistem berbasis komputer untuk kalibrasi, akuisisi, dan rekonstruksi dan visualisasi data usg 3-dimensi," vol. 2006, no. Snati, 2006.

[7] G. Vasavi and S. Jyothi, "A Comparative Study of Speckle Reduction Filters for Ultrasound Images of Poly Cystic Ovary," no. 6, pp. 2084-2089, 2019.

[8] A. H. Hamad, H. O. Muhamad, and S. P. Yaba, "De-noising of medical images by using some filters," vol. 2, no. July 2014, 2015.

[9] I. Technology, C. Science, and C. Science, "Pre-diagnosis of lung cancer using feed forward neural network and back," vol. 3, no. 9, pp. 3313-3319.

[10] P. Deepa and M. Suganthi, "Performance Evaluation of Various Denoising Filters 
for Medical Image," vol. 5, no. 3, pp. 4205-4209, 2014.

[11] M. A. Gungor, I. Karagoz, and E. Engineering, "The Effects of the Median Filter with Different Window Sizes for Ultrasound Image," pp. 549-552, 2016.

[12] A. S. Bafaraj, "Performance Analysis of Best Speckle Filter for Noise Reduction in Ultrasound Medical Images," vol. 14, no. 6, pp. 1340-1351, 2019.

[13] A. S. Y. Bin-habtoor and S. S. Al-amri, "Removal Speckle Noise from Medical Image Using Image Processing Techniques," vol. 7, no. 1, pp. 375-377, 2016. 